\title{
Study the acceptance, compliance and efficacy of injection depot medroxy progesterone acetate as contraception: a prospective observational study
}

\author{
Nupur S. Mane, Jyoti V. Rokade*
}

Department of Obstetrics and Gynaecology, Govt. Medical College, Miraj, Maharashtra, India

\author{
Received: 06 November 2020 \\ Revised: 16 December 2020 \\ Accepted: 17 December 2020 \\ *Correspondence: \\ Dr. Jyoti V. Rokade, \\ E-mail: jyotivikasrokade@gmail.com
}

Copyright: (C) the author(s), publisher and licensee Medip Academy. This is an open-access article distributed under the terms of the Creative Commons Attribution Non-Commercial License, which permits unrestricted non-commercial use, distribution, and reproduction in any medium, provided the original work is properly cited.

\begin{abstract}
Background: India was the first country in the world to launch a family planning programme, as early as 1952, with the main aim of controlling its population. Depot medroxy progesterone acetate, or DMPA is a progestin-only method of contraception. It is a 3-monthly intramuscular injectable that delivers $150 \mathrm{mg}$ of medroxyprogesterone acetate in microcrystalline suspension form that delays absorption of the hormone after the injection. It provides long acting, effective and reversible contraception. In this study, we evaluated patients in reproductive age group 18-35 years who were willing to use injectable DMPA as a method of contraception to study the acceptance, compliance and efficacy of injection depot medroxyprogesterone acetate as contraception.

Methods: It is a prospective observational study carried out at Government medical college Miraj on 150 patients who fulfil the inclusion criteria. The postpartum, interval and postabortal categorisation of patients done and they are councelled about the benefits and side effects and drawbacks of DMPA. Injection is given deep intramuscularly after written informed consent and a DMPA card is given to beneficiary. Follow up date explained and patients are observed for follow up and any evidence of bleeding weight gain or any other side effects of DMPA are noted.

Results: The mean age of subjects was $24.48 \pm 3.494$ years. 2) $3.3 \%$ of the patients were nullipara, primi para $46.7 \%$, $36 \%$ were second para, $11.3 \%$ were third para and $2.7 \%$ were fourth par. 3) After $1^{\text {st }}$ injection, $47.3 \%$ patients were lost to follow-up i.e., they did not turn up for their second dose of injection. 4) Out of 150 patients who accepted the injection as contraception, only 79 patients turned up for their $2^{\text {nd }}$ injection after 3 months, out of which only 37 patients turned up for their $3^{\text {rd }}$ dose of injection after 6 months and only 5 patients turned up for their $3^{\text {rd }}$ injection. Thus showing that the compliance is poor among this study population. 5) At $2^{\text {nd }}$ injection, $39.2 \%$ discontinued due to amenorrhea, $10.7 \%$ discontinued due to irregular bleeding, $18.5 \%$ due to weight gain and $31.6 \%$ due undergoing permanent method. 6) No patients who came for follow up reported any pregnancies during the course of injection, therefore the efficacy of injection depot medroxy-progesterone acetate, as a method of contraception is $100 \%$ in this study.

Conclusions: The DMPA is a good method of long acting reversible method of contraception with good acceptance and efficacy with less compliance.
\end{abstract}

Keywords: DMPA, Long acting reversible contraception

\section{INTRODUCTION}

India's population has already reached 1.26 billion and considering the high decadal growth rate of 17.64 , the country's population is slated to surpass that of China by 2028(UNDP). The challenge now has extended beyond 
population stabilization to addressing sustainable development goals for maternal and child health. ${ }^{1}$

According to NFHS-3, around $30 \%$ of the fertility in India was unwanted, indicating a huge gap between the demand and supply of family planning measures. The unmet need for contraception in the country as a whole is about $13 \%$. Reasons for this include: limited choice of methods, limited access to contraception, particularly among young people, poorer segments of populations, or unmarried people, fear of experiencing side effects, cultural or religious opposition, poor quality of available services, users and providers bias, gender-based barriers. ${ }^{2}$

The desired features of an "ideal contraceptive" are as follows: Safe, effective, acceptable, inexpensive, reversible, simple to administer, independent of coitus, long lasting, requiring little or no medical supervision. ${ }^{3}$

Depot medroxy progesterone acetate, or DMPA is a progestin-only method of contraception. It is a long acting reversible contraceptive. It is a 3-monthly intramuscular injectable that delivers $150 \mathrm{mg}$ of medroxyprogesterone acetate in microcrystalline suspension form that delays absorption of the hormone after the injection. It provides long acting, effective and reversible contraception. ${ }^{4}$

It is accepted by women who cannot remember to take OC pills regularly and by those who do not wish to insert an IUD. Theoretical concerns with early postpartum administration of DMPA remain that of infant safety, premature inhibition of lactation and its metabolic effects on mother. Studies indicate that effect of DMPA on infant health and lactation are unfounded. ${ }^{5-7}$

Injectable contraceptives were not included in Government of India family planning program because of fears expressed by many authorities about their appropriateness and quality of services. ${ }^{8}$

However, the new contraceptive Injectable DMPA under "Antara Programme" was launched in 2017 free of cost by Ministry of Health \& Family Welfare, India and have been added to the existing contraceptive basket of choice thus providing users with new options. ${ }^{9}$

In this study, we evaluated patients in reproductive age group 18-35 years who were willing to use injectable DMPA as a method of contraception to study the acceptance, compliance and efficacy of injection depot medroxyprogesterone acetate as contraception.

\section{METHODS}

A prospective observational study was conducted at GMC, Miraj for a period of 18 months. All eligible women were given choice of contraceptive options and explained well about the benefits and side effects of each contraceptive method. Those who chose DMPA as a method of contraception were included in this study. A total of 150 women willing to take the injection were included in the study and their follow-up visits were noted subsequently. The data collected was analysed using SPSS software version 17 .

\section{Inclusion criteria}

The patients in reproductive age group 18-35 yrs who wish to use the method as contraception. Post abortal patients within 7 days of abortion. Patients delivered $1 \frac{1}{2}$ month back and want contraception who are not able to follow lactational amenorrhea method. Patients delivered 6 months back and want contraception.

\section{Exclusion criteria}

Patients not willing to participate in the study. Patients below 18yrs and above 35yrs.

In our setting, patients eligible for DMPA injection were counselled regarding the frequency, mode of injection, side effects, changes in the pattern of menses and minor ailments like weight gain, mood changes etc. Patients were also counselled regarding the reversibility of fertility upon discontinuation. A written informed consent was taken from the patients. Injection DMPA $150 \mathrm{mg}$ available at our institute was a prefilled syringe which was stored at room temperature. With all aseptic precautions the injection was given intramuscularly in the gluteal region. Care was taken to ensure that the injection was given either in the first week of menses, immediate post abortal or at $40-45$ days of post partum period.

When the injection was given in the first week of menses, no backup method of contraception was advised to the patients. When it was given after 7 days of menstrual cycle, backup method (e.g. condom) for the first 7 days after the injection was advised. If the women failed to follow up on the given date for the next dose of injection and if she had history of amenorrhea, she was advised to take a urine pregnancy test to rule out pregnancy before she was given the next dose. A DMPA card was filled with patient details in two parts- one was given to the patient \& other was with the hospital. A separate register was maintained in the hospital ward. The data from the DMPA Card and register was used to determine the following parameters:

- Acceptance of the injection is the number of patients willing to take the injection after counselling.

- Compliance of the injection is the number of patients coming for regular follow up. 
- Efficacy of the injection is the number of patients not conceiving while using injection Depot Medroxy Progesterone Acetate as contraception.

\section{RESULTS}

Mean age of subjects was $24.48 \pm 3.494$ years. Majority of subjects were in the age group 21 to 25 years (53.3\%), $30.7 \%$ were in the age group 26 to 30 years, $12 \%$ were in the age group $<20$ years, $4 \%$ were in the age group 31 to 35 years.

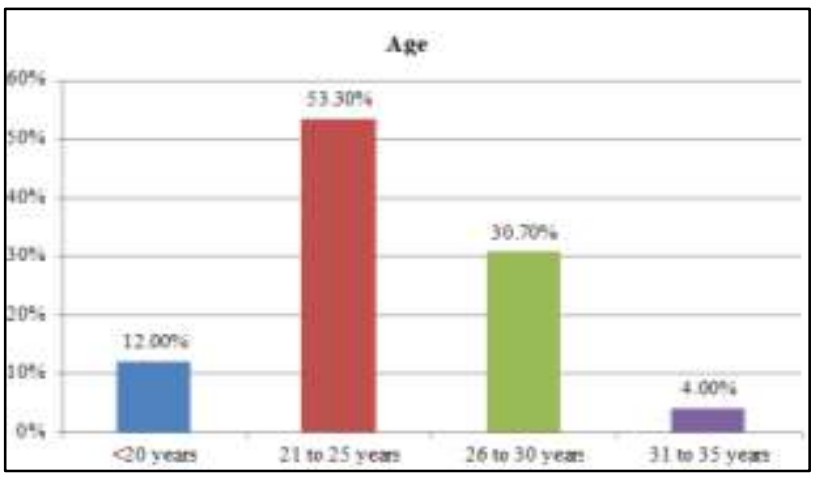

Figure 1: Age distribution among subjects.

In the study $3.3 \%$ were Nullipara, primipara were $46.7 \%$, $2^{\text {nd }}$ para were $36 \%, 3^{\text {rd }}$ para were $11.3 \%$ and $4^{\text {th }}$ para were $2.7 \%$.

Table 1: Parity distribution among subjects.

\begin{tabular}{|llll|}
\hline \multirow{5}{*}{ Parity } & & Count & $\%$ \\
\cline { 2 - 4 } & Nullipara & 5 & 3.3 \\
\cline { 2 - 4 } & 1 & 70 & 46.7 \\
\cline { 2 - 4 } & 2 & 54 & 36.0 \\
\cline { 2 - 4 } & 3 & 17 & 11.3 \\
\cline { 2 - 4 } & 4 & 4 & 2.7 \\
\hline
\end{tabular}

In the study $59.3 \%$ had interval injection, $18.7 \%$ had post partum injection and $22 \%$ had post abortal injection.

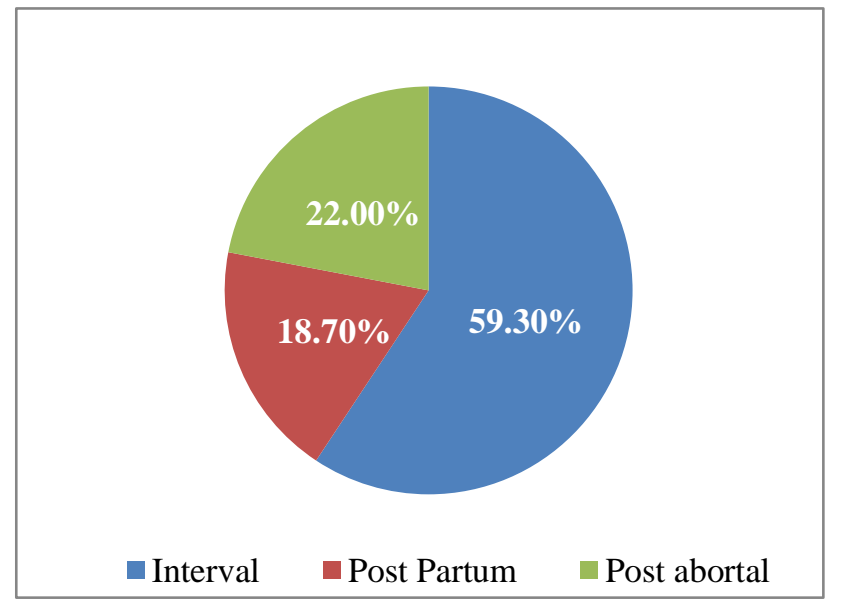

Figure 2: Timing of injection distribution.
In this study, after $1^{\text {st }}$ injection, $47.3 \%$ patients were lost to follow-up i.e., they did not show up for their second dose of injection.

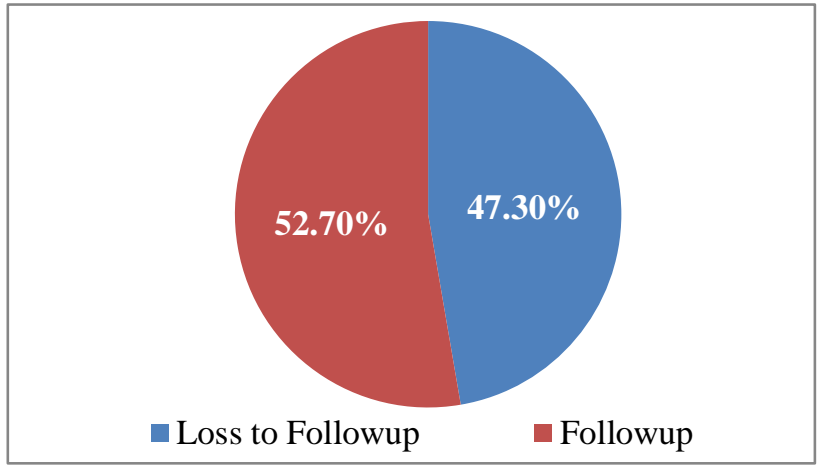

Figure 3: Lost to follow-up.

In the study, patients who came for $2^{\text {nd }}$ injection, $59.4 \%$ had amenorrhea, $22.6 \%$ had irregular bleeding and $18 \%$ had increased weight whereas patients who came for $3^{\text {rd }}$ injection, $65 \%$ had amenorrhea, $29.7 \%$ had Irregular bleeding and $5 \%$ had increased weight.

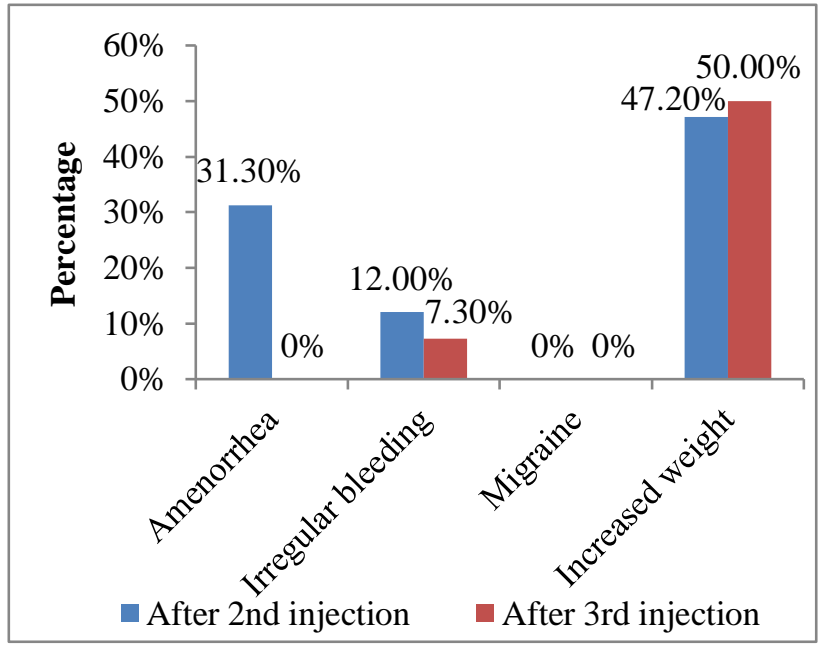

Figure 4: Complications among subjects after second injection and $3^{\text {rd }}$ injection.

Table 2: Discontinuation rate.

\begin{tabular}{|lllll|}
\hline $\begin{array}{l}\text { Discontinuation } \\
\text { rate }\end{array}$ & \multicolumn{2}{c|}{ Continued } & \multicolumn{2}{c|}{ Discontinued } \\
\hline After 1 $1^{\text {st }}$ dose & 79 & $52.7 \%$ & 71 & $47.3 \%$ \\
\hline After 2 $2^{\text {nd }}$ dose & 37 & $46.9 \%$ & 42 & $53.1 \%$ \\
\hline After $3^{\text {rd }}$ dose & 5 & $13.6 \%$ & 32 & $86.4 \%$ \\
\hline
\end{tabular}

In this study, continuity rate decreased from $52 \%$ to $13 \%$, from the second dose to fourth dose. In this study, after $1^{\text {st }}$ dose $47.3 \%$ patients discontinued, after $2^{\text {nd }}$ dose $53.1 \%$ patients. discontinued and after $3^{\text {rd }}$ dose, $86.4 \%$ patients discontinued the injection. This showed that the discontinuity rate increased as the number of injections taken increased. 
In the study, at $2^{\text {nd }}$ injection, most common cause for discontinuation was amenorrhea $(39.2 \%)$ followed by permanent sterilization/ bilateral tubal ligation (31.6\%), followed by irregular bleeding $(10.7 \%)$ and by weight gain $(18.5 \%)$.

At $3^{\text {rd }}$ injection, $29.7 \%$ discontinued due to irregular bleeding and $70.3 \%$ discontinued as they went for bilateral tubal ligation as they had completed their families.

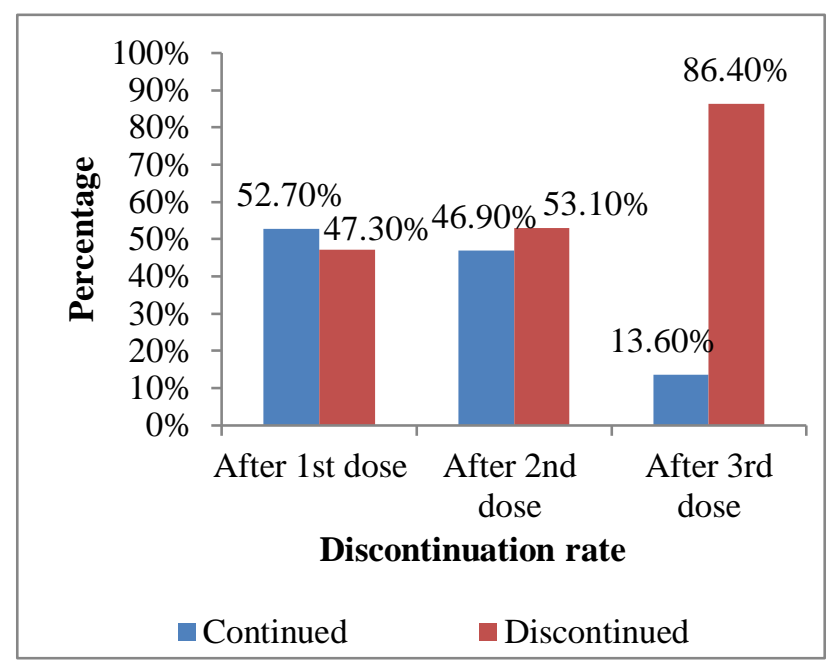

Figure 5: Discontinuation due to complications.

\section{DISCUSSION}

In this study, mean age of subjects was 24.48 \pm 3.494 years. A study by Rai L et al, Sirisha PSNRS, Nautiyal R et al, the mean age of women was 26.6 years, 25 years and 26.5 years respectively..$^{10,12,14}$

In this study, $3.3 \%$ were nullipara, primi para in $46.7 \%$, $2^{\text {nd }}$ para in $36 \%, 3^{\text {rd }}$ para in $11.3 \%$ and $4^{\text {th }}$ para in $2.7 \%$ and accepted injection depot medroxy-progesterone acetate as a temporary method of contraception. In a study by Nautiyal R et al, $51 \%$ patients were primiparas while $49 \%$ were multiparas whereas in a study by Rai L et al $2007,73 \%$ per cent of the women were primipara while the remaining $27 \%$ were multiparous. ${ }^{14}$

In this study, $59.3 \%$ of patients in interval period, $18.7 \%$ in post-partum period and $22 \%$ in post abortal patients. A study by Lavanya Rai et al $2007,51 \%$ of the respondents were post-partum while the rest were either postabortal or interval users. ${ }^{10}$ In a case study by Dr. Pratibha Singh et al 2015, out of 500 selected cases, 75\% took DMPA Postdelivery and $47 \%$ took in postabortal period. ${ }^{13}$

In this study, after 1 stinjection, $47.3 \%$ patients were lost to follow-up i.e., they did not turn up for their second dose of injection. In the study by Michelle Fonseca et al 2017, most of the women 146 (73\%) had lost to follow up after $1^{\text {st }}$ injection. ${ }^{11}$ While in a study conducted by Sirisha
PSNRS 2017, 21.2\% patients had lost to follow up after $1^{\text {st }}$ injection. $^{12}$

In the study, patients who came for $2^{\text {nd }}$ injection, $59.4 \%$ had amenorrhea, $22.6 \%$ had irregular bleeding and $18 \%$ had increased weight whereas patients who came for $3^{\text {rd }}$ injection, $65 \%$ had amenorrhea, $29.7 \%$ had irregular bleeding and $5 \%$ had increased weight. A study by Rai L et al shows irregular bleeding $(70 \%)$ and amenorrhoea $(65 \%)$ were the most common side-effects. ${ }^{10}$ In a case study by Singh P et al 2015, out of 500, about $70 \%$ had an amenorrhea, and $50 \%$ had an irregular bleeding. ${ }^{13}$

In this study, compliance of the injection was the number of patients coming for regular follow up. Out of 150 patients who accepted the injection as contraception, only 79 patients turned up for their $2^{\text {nd }}$ injection after 3 months, out of which only 37 patients turned up for their $3^{\text {rd }}$ dose of injection after 6 months and only 5 patients turned up for their $3^{\text {rd }}$ injection. Thus, showing that the compliance is poor among this study population. A study conducted by Sirisha PSNRS 2017 showed that $58.58 \%$ came back for the second dose, and only $36.36 \%$ continued with the third dose. ${ }^{12}$

In the study, at $2^{\text {nd }}$ injection, $39.2 \%$ discontinued due to amenorrhea, $10.7 \%$ discontinued due to irregular bleeding, $18.5 \%$ due to weight gain and $31.6 \%$ due undergoing permanent method of sterilization (i.e. bilateral tubal ligation) as their families were completed. At $3^{\text {rd }}$ injection, $29.7 \%$ discontinued due to irregular bleeding and $70.3 \%$ discontinued as they went for permanent method of sterilization (i.e. bilateral tubal ligation) as they had completed their families. In a study conducted by Sirisha PSNRS 2017, menstrual disturbances $(40 \%)$ were found to be the main reasons for discontinuation. ${ }^{12}$ Among the menstrual disturbances amenorrhea $\mathrm{w}$ a $\mathrm{s}$ the main reason stated for the cause of discontinuation even.

No patients who came for follow up reported any pregnancies during the course of injection, therefore the efficacy of injection depot medroxy-progesterone acetate, as a method of contraception is $100 \%$ in this study. In the study conducted by Sirisha PNRS, there was no pregnancy noted during their course of study, hence the efficacy was $100 \% .^{12}$

\section{CONCLUSION}

Long acting reversible contraception is a safe, effective, freely available, with less contraindications method of fertility control. The acceptance of the method is more as it is free and also for interval and postaboratal method of contraception. It is the best method where there is contraindication for the use of progesterone with very good efficacy. The important drawbacks of DMPA constitute intermitant spotting, amenorrea, weight gain and delayed return of fertility. These definitely have an impact on compliance and in our study the compliance 
went on reducing with further doses of injection. It is probably the same reason why this method did not gain much welcome.

This study has several limitations. Sample size was less. Duration of the study was less. Duration required was atleast 5 years to assess all objectives. During follow up, patients who were traced using their phone numbers was not possible as their phones were not reachable or switched off. Therefore they were lost to follow up.

Funding: No funding sources

Conflict of interest: None declared

Ethical approval: The study was approved by the Institutional Ethics Committee

\section{REFERENCES}

1. National Health Mission, Government of India, $2016 . \quad$ Available at: http://www.nhmmp.gov.in/WebContent/FW/Scheme /Scheme2017/Mission_Parivar_Vikas.pdf.

2. Ventura SJ, Abma JC, Mosher WD, Henshaw SK. Estimated pregnancy rates for the United States, 1990-2005: an update. Natl Vital Stat Rep. 2009;58:1-14.

3. Park K. Demography and family planning. In: Park K. Park's Textbook of Preventive and Social Medicine, 24th ed. Jabalpur, India: Banarsidas Bhanot Publishers, 2017:525-552.

4. Westoff C. Depot medroxyprogesterone acetate injection: a highly effective contraception with proven long term safety. Contraception. 2011;68(2):75-87.

5. Brownell EA, Fernandez ID, Howard CR, Fisher SG, Ternullo SR, Buckley RJ, Dozier AM. A systematic review of early postpartum medroxyprogesterone receipt and early breastfeeding cessation: evaluating the methodological rigor of the evidence. Breastfed Med. 2012;7(7):10-8.
6. ACOG Practice Bulletin no 73. Use of hormonal contraception in women with medical disorders. Obstet Gynecol. 2019;107:1453-72.

7. Rodrigues MI, Kaunitz AM. An evidence of postpartum use of DMPA in breastfeeding women. Contraception. 2009;80(1):4-6.

8. Sarojini NB, Murthy L. Why women's groups oppose injectable contraceptives. Indian J Med Ethics. 2005;2(1):8-9.

9. Department Health Family Welfare. Annual report, 2017-18. Available at: https://mohfw.gov.in/documents/publications/annual -report-department-health-family-welfare-year-201718/annual-report-department-health-family-welfareyear-2017-18.

10. Rai L, Prabakar P, Nair S. Injectable depot medroxyprogesterone-a safe and an effective contraception for an Indian setting,". Health Popu Perspect Issu. 2007;30(1):12-23.

11. Fonseca M, Deshmukh PY, Kharat D. DMPA: acceptance and compliance in a tertiary care hospital in Mumbai, India. Int J Reprod Contracept Obstet Gynecol. 2017;6:3879-81.

12. Sirisha PSNRS. Efficacy of depot medroxyprogesterone acetate as a contraceptive. Intern J Med Res Pharma Sci. 2017;4(12).

13. Singh P, Vyas RC. Ushma., Yadav, P. Study of Effectiveness of DMPA in Postpartum and Postabortal Period. J Dent Med Sci. 2015;14(2):74-8.

14. Nautiyal R, Bijalwan R, Maithili B, Sinha LN. Feasibility of injectable Depot medroxyprogesterone acetate in a semi urban camp setting. Int $\mathbf{J}$ Reprod Contracept Obstet Gynecol. 2016;5:1056-60.

Cite this article as: Mane NS, Rokade JV. Study the acceptance, compliance and efficacy of injection depot medroxy progesterone acetate as contraception: a prospective observational study. Int J Reprod Contracept Obstet Gynecol 2021;10:303-7. 